\title{
Long-term effects of hyperproteic diet on functional renal reserve and natriuresis
}

\author{
Edwin R. Castillo Velarde ${ }^{*(\mathbb{D})}$ \\ Universidad Ricardo Palma, Lima, Perú
}

\section{AR T I C L E I N F O}

Article Type:

Original

\section{Article History:}

Received: 9 September 2020

Accepted: 4 October 2020

Published online: 29 October 2020

\section{Keywords:}

Hyperproteic diet

Hypersodic diet

Glomerular filtration rate

Natriuresis

Renal functional reserve

\begin{abstract}
A B S T RA C T
Introduction: A hyperproteic diet normally results in acute changes in renal function evidenced by increases of natriuresis and glomerular filtration rate (renal functional reserve).

Objectives: To assess the changes in natriuresis and creatinine clearance during 12 weeks on hyperproteic and hypersodic diet.

Materials and Methods: Eighteen adults male Holtzman rats were included and the follow-up period was 12 weeks. The rats were initially distributed into three groups; hyperproteic diet $(30 \%)$ from an animal source $(n=6)$, hyperproteic diet $(30 \%)$ from a plant source $(n=6)$ and normoproteic $\operatorname{diet}(18 \%)$ from an animal source $(\mathrm{n}=6)$. The diets were isocaloric, normosodic $(0.25 \%)$. From week 8 , each group was divided into three rats each and received a high-sodium (1.5\%) and normosodic diet $(0.25 \%)$ respectively.

Results: The hyperproteic diet group (animal or plant vegetal source) had higher creatinine clearance than normoproteic diet $(P<0.05)$. The hyperproteic vegetal diet group had a peak with an increased renal functional reserve in $21 \%(P=0.04)$. The natriuresis increased in the group on the animal-source diet during the first 2 weeks $(P=0.03)$. The group plant-source diet did not have significant change at the first week $(P=0.50)$; however, there was a subsequent decrease in the level of natriuresis between weeks 3 to 8 . When the groups were exposed to a hypersodic diet, there was not difference in the natriuretic response between the groups $(P>0.05)$.

Conclusion: A hyperproteic vegetal diet increased renal functional reserve but not natriuresis during an acute or long-term period; however, the natriuretic response was not impaired when a hypersodic diet was added, though hyperfiltration was present.
\end{abstract}

Implication for health policy/practice/research/medical education:

Reseach in natriuresis and renal functional reserve and implications on hypeproteic diet.

Please cite this paper as: Castillo Velarde ER. Long-term effects of hyperproteic diet on functional renal reserve and natriuresis. J Renal Inj Prev. 2021; 10(2): e13. doi: 10.34172/jrip.2021.13.

\section{Introduction}

Acute exposure of a hyperproteic diet induces an increase in glomerular filtration rate (GFR), plasmatic renal flow, decrease in renal vascular resistance and an increase in natriuresis (1-3). There are few reports about long-term changes of natriuresis and renal functional reserve.

A hyperproteic diet normally results in acute changes in renal function evidenced by increases of natriuresis and GFR (renal functional reserve). Modulation of natriuresis mainly has been reported through prostaglandins, angiotensin 2, natriuretic peptides and cinine-kalikrein (4). When hyperfiltration is persistent, there are autoregulation mechanisms on natriuresis, for example, primary tubular reabsorption. Pathologically, a long- term hyperproteic diet could induce sustained sodium reabsorption on excess protein intake (5).

\section{Objectives}

The objective of this study was to assess the acute and long-term changes in natriuresis and creatinine clearance when a chronic hyperproteic diet and saline overload was administrated. The previous reports analyze only acute changes, for example, GFR concerning hyperproteic diet $(6,7)$. This study evaluates expected increases of GFR on hyperproteic diet (renal functional reserve $(8,9)$ during the acute and long term. Natriuresis is measured to compare changes on normosodic and hypersodic diets. 


\section{Materials and Methods}

\section{Study design}

Eighteen adults male Holtzman rats between 8 and 14 weeks of life were included in the study, and the follow-up period was 12 weeks. The rats were initially distributed into three groups. The first group received a hyperproteic diet (30\%) from an animal source (n:6), the second group received a hyperproteic diet (30\%) from a plant source $(n: 6)$ and the third group received a normoproteic diet (18\%) from an animal source (n:6). The nutritional analysis was performed from soybean and poultry source. The diets were isocaloric, normosodic $(0.25 \%)$ and water ad libitum. From week 8, each group was divided into three rats each and received a high-sodium (1.5\%) and normosodic diet $(0.25 \%)$ respectively. Periodic checks were performed to measure the 24-hour natriuresis (flame photometry, normal values of $28-190 \mathrm{mmol} / 24$ hours) in weeks $0,1,2,3,4,6,8,9,11,12$ and glomerular filtration rate (Jaffe reaction, creatinine normal value of 0.4-1.4 $\mathrm{mg} / \mathrm{dL}$ ) in weeks $0,4,8,12$. (Supplementary file 1 ). The method of euthanasia used thiopental by intraperitoneal injection.

The source of diets were analyzed by Certified Total Quality Laboratory La Molina (http://www.lamolina. edu.pe/calidadtotal/fisico_quimico.htm) and is showed in Table 1. The plant source was soy, its protein content $47 \%$. The animal source was poultry, its protein content $77 \%$. There were higher levels of essential, aromatic and branched chain amino acids in poultry meal than the plant source (Table 2).

The minimum concentration of proteins required for the growth of rats is estimated at approximately $15 \%$ and most of the food produced contains between 18 and 25\% (10,11). This investigation defined a normoproteic diet at a protein concentration of $18 \%$. The hyperproteic diet corresponds to a caloric intake derived from proteins in more than $25 \%$. The hyperproteic diet was defined a concentration of $30 \%$ (5). The salt requirements for growth are estimated at $0.05 \%$ and that in a $400 \mathrm{~g}$ rat it is equivalent to a consumption of $10 \mathrm{mg} /$ day of sodium or $25 \mathrm{mg} / \mathrm{kg}$. Some commercial diets have a sodium concentration of 0.3 to $0.5 \%$, however, this amount exceeds the requirements, and is equivalent to a consumption of $100 \mathrm{mg} / \mathrm{d}$ or $250 \mathrm{mg} / \mathrm{kg}$ (12). In human nutrition, a consumption of $2400 \mathrm{mg} / \mathrm{d}$ of sodium or $34 \mathrm{mg} / \mathrm{kg}$ is recommended. A value of $0.25 \%$
Table 2. Composition of soybean and poultry meal. The dates are show in percentage

\begin{tabular}{lcc}
\hline & Soybean meal & Poultry meal \\
\hline Dry matter & 90.0 & 94.0 \\
Protein & 47.0 & 77.3 \\
Fiber & 4.0 & 0.57 \\
\hline Fat & 1.0 & 12 \\
Lysine & 2.96 & 4.43 \\
\hline Methionine & 0.67 & 0.82 \\
Arginine & 3.48 & 4.49 \\
Threonine & 1.87 & 3.31 \\
\hline Tryptophan & 0.74 & 0.60 \\
Glycine & 2.02 & 0.0 \\
Histidine & 1.28 & 2.26 \\
Leucine & 3.72 & 7.04 \\
\hline Isoleucine & 2.12 & 2.24 \\
Phenylalanine & 2.34 & 0.0 \\
Valine & 2.22 & 5.38 \\
\hline
\end{tabular}

and $1.5 \%$ were defined as normosodic and hypersodic respectively.

\section{Ethical issues}

This study was confirmed by Local Ethics Committee of department of Physiology at San Marcos University. As an experiment, the protocols were approved to be in accordance with the guidelines for the Care and Use of Laboratory Animals by the National Academy of Sciences (National Institutes of Health). This study was extracted from the MSc thesis of Edwin Castillo at this University (https://cybertesis.unmsm.edu.pe/ handle/20.500.12672/3925).

\section{Data analysis}

Statistical analysis used Wilcoxon test to compare two related samples and Friedman statistical test to compare more than two dependent samples (GFR or natriuresis during follow-up). Mann-Whitney U and Kruskal Wallis were used to compare two or more than two independent samples, respectively (GFR or natriuresis between diets groups).

Results

At baseline (week 0) the mean of creatinine was $0.54 \mathrm{mg} /$

Table 1. Analysis of experimental diets

\begin{tabular}{lccc}
\hline & Normoproteic animal diet & Hyperproteic animal diet & Hyperproteic vegetal diet \\
\hline Protein $(\mathrm{g} / 100 \mathrm{~g})$ & 18.3 & 28.9 & 30.1 \\
Humidity $(\mathrm{g} / 100 \mathrm{~g})$ & 9.3 & 8.1 & 7.5 \\
Fat $(\mathrm{g} / 100 \mathrm{~g})$ & 5.3 & 4.7 & 8.1 \\
Ash $(\mathrm{g} / 100 \mathrm{~g})$ & 4.9 & 50.8 & 6.5 \\
Carbohydrate $(\mathrm{g} / 100 \mathrm{~g})$ & 62.2 & 386.3 & 47.0 \\
\hline Total energy $(\mathrm{kcal} / 100 \mathrm{~g})$ & 369.7 & 381.3 \\
\hline
\end{tabular}


$\mathrm{dL}$, weight $242 \mathrm{~g}$ and the control of creatinine clearance was homogeneous between groups $(P>0.05)$. The hyperproteic diet group (animal or vegetal) had higher creatinine clearance than the group given the normoproteic diet at weeks 4 and $8(P<0.05)$. The hyperproteic vegetal diet group increased renal functional reserve in $21 \%$ $(P=0.04)$ and the hyperproteic animal diet group did not have significant changes $(P>0.05)$. The normoproteic animal diet group reduced creatinine clearance between weeks 4 to 8 . All the groups had no significant changes in creatinine clearance after salt overload.

The group on the animal-source diet increased natriuresis more than 1.5 -fold from baseline during the first 2 weeks $(P=0.03)$ and the group plant-sourced diet did not have significant change in the first week $(P=0.50)$. After, reduce their natriuresis between weeks 2 to 8 $(P<0.05)$. The groups on the animal-sourced diet had a subsequent decrease in the level of natriuresis between weeks 3 to 8 (Table 3 ).

There was higher creatinine clearance on the animal or plant hyperproteic diet than normoproteic diet at weeks 4 and 8 , but not of natriuresis (Figure 1). The natriuretic response was not impaired when the groups were exposed to a hypersodic diet during week 8 to 12 and there were no differences between the groups $(P>0.05)$, even though natriuresis had previously decreased as renal functional reserve increased, specifically during peak at week 8 in hyperproteic vegetal diet.

\section{Discussion}

These findings show that a vegetal hyperproteic diet had higher renal functional reserve but not increased natriuresis. The vegetal hyperproteic diet increased functional renal reserve, even though the animal protein source had higher levels of arginine and methionine, which is typically related to hyperfiltration. Compared to the normoproteic diet group, the hyperproteic animal or plant group had higher levels of GFR.

Previous research has established a linear correlation between GFR ( $\mathrm{mL} / \mathrm{min} / 100 \mathrm{~g} \mathrm{BW}$ ) and increased up to weight of about 120-150 g. When the rats over $150 \mathrm{~g}$, the GFR had not run parallel with the increase in weight. Then, there is a constant decrease in the GFR/100 g BW (13). The results are in line with this previous report. The weight at baseline was $242 \mathrm{~g}$ and the GFR subsequently decreased slowly in animal-source diet groups, except in hyperproteic vegetal diet group. There was a significance difference between hyperproteic and normoproteic diet groups independent of the slow reduction of GFR.

It was outstanding to observe hyperfiltration and reduced natriuresis in hyperproteic vegetal diet during week 8 . More studies are needed to investigate this point. This mechanism cannot be explained by tubuloglomerular feedback or by a synthesis of prostaglandins because they simultaneously increase glomerular filtration and natriuresis. Thus, another possible mechanism is the effect of angiotensin, which can increase sodium tubular reabsorption by AT1 and increase glomerular filtration by changing glomerular hemodynamics at efferent arterioles. During weeks 8 to 12 , when a hypersodic diet was added, the natriuretic response was not impaired, so in the hypothesis of angiotensin, its sustained increased under hyperproteic diet would not disable the natriuretic response by a saline overload.

\section{Conclusion}

A long-term hyperproteic vegetal diet and subsequently increases in GFR not impaired physiological increases in natriuresis when a salt overload is administrated in an experimental model.

Table 3. Control of natriuresis and creatinine clearance

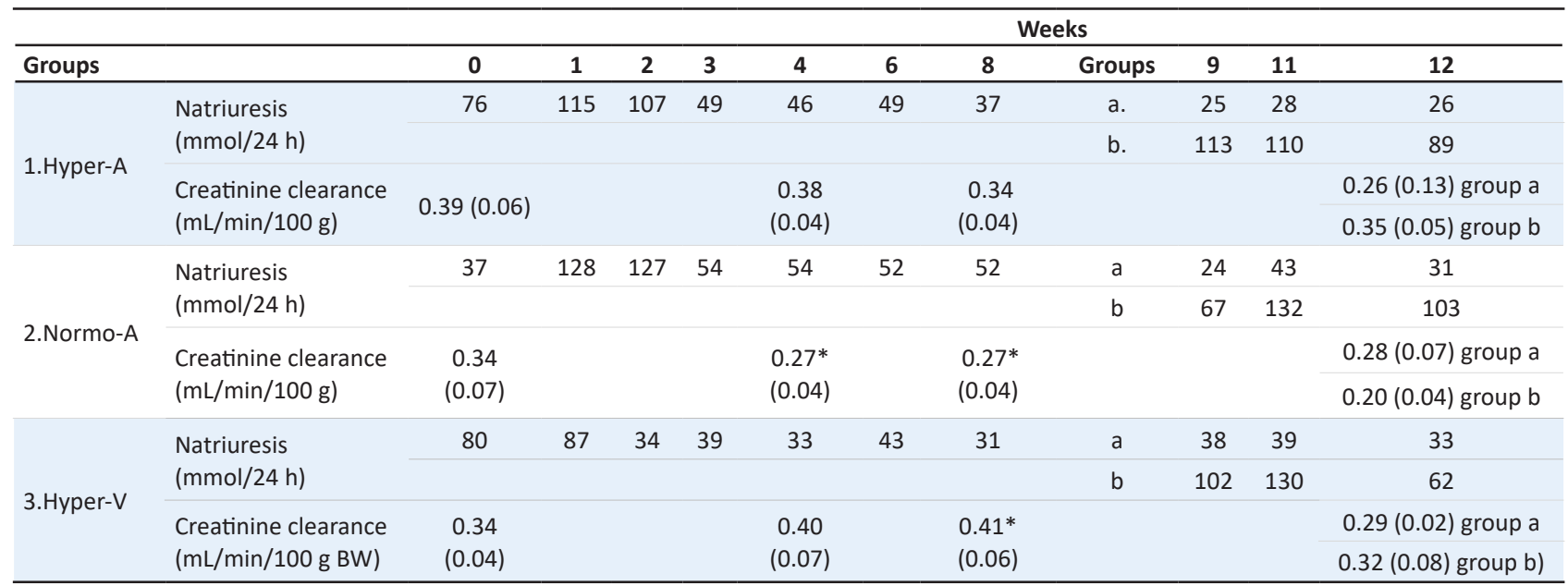

The groups were hyperproteic animal (Hyper-A), normoproteic animal (Normo-A), and hyperproteic vegetal (Hyper-V). From week 1 to 8 the diets were normosodic. From week 8 to 12 each group was separate in normosodic (a) and hypersodic (b) groups. 


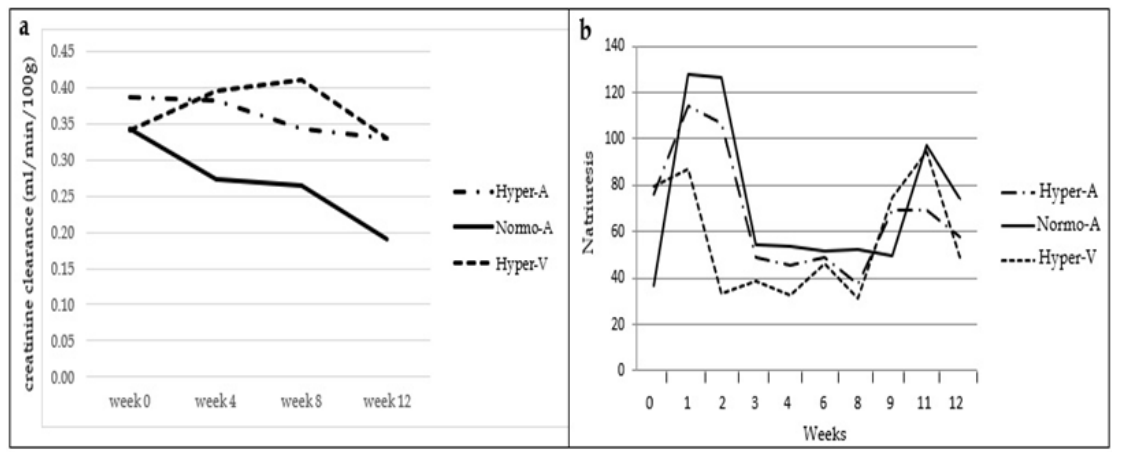

Figure 1. There was higher creatinine clearance on the animal or plant hyperproteic diet than normoproteic diet at weeks 4 and 8 , but not of natriuresis

\section{Limitations of the study}

This research could have included more rats in each group to avoid a type II error possibility, specially to assess changes of GFR on hyperproteic animal diet. However, the means and standard deviation were given, hence, this possibility was unlikely.

\section{Acknowledgments}

The author thanks Lic. Hilda Palomino Leoyacc from Biochemistry Laboratory at Hospital Almenara, Lima, Perú.

\section{Author's contribution}

Conception and design of the study, generation, collection, assembly, analysis and interpretation of data; revision of the manuscript; approval of the final version of the manuscript.

\section{Conflicts of interest}

The author declares no competing interests.

\section{Ethical considerations}

Ethical issues (including plagiarism, data fabrication, double publication) have been completely observed by the author.

\section{Funding/Support}

None.

\section{Supplementary files}

Supplementary file 1 contains Table S1.

\section{References}

1. Gabbai FB. The role of renal response to amino acid infusion and oral protein load in normal kidneys and kidney with acute and chronic disease. Curr Opin Nephrol Hypertens. 2018;27:23-29. doi: 10.1097/MNH.0000000000000380.
2. Fernández-Repollet E, Van Loon P, Martínez-Maldonado M. Renal and systemic effects of short-term high protein feeding in normal rats. Am J Med Sci. 1989;297: 348-54. doi: 10.1097/00000441-198906000-00003.

3. Tolins JP, Raij L. Effects of amino acid infusion on renal hemodynamics. Role of endothelium-derived relaxing factor. Hypertension. 1991;17:1045-51. doi: 10.1161/01. hyp.17.6.1045.

4. Castrop H, Höcherl K, Kurtz A, Schweda F, Todorov V, Wagner C. Physiology of kidney renin. Physiol Rev. 2010; 90:607-73. doi: 10.1152/physrev.00011.2009.

5. Friedman AN. High-protein diets: potential effects on the kidney in renal health and disease. Am J Kidney Dis. 2004;44:950-62. doi: 10.1053/j.ajkd.2004.08.020.

6. Jaffa AA, Silva RH, Kim B, Mayfield RK. Modulation of renal kallikrein production by dietary protein in streptozotocininduced diabetic rats. J Am Soc Nephrol. 1996;7:721-7.

7. Kontessis P, Jones S, Dodds R, Trevisan R, Nosadini R, Fioretto $\mathrm{P}$, et al. Renal, metabolic and hormonal responses to ingestion of animal and vegetable proteins. Kidney Int. 1990;38:136-44. doi: 10.1038/ki.1990.178.

8. Heguilén RM, Liste AA, Bellusci AD, Lapidus AM, Bernasconi AR. Renal response to an acute protein challenge in pregnant women with borderline hypertension. Nephrology (Carlton). 2007;12:254-60. doi: 10.1111/j.14401797.2007.00790.x.

9. Esposito C, Plati A, Mazzullo T, Fasoli G, De Mauri A, Grosjean F, et al. Renal function and functional reserve in healthy elderly individuals. J Nephrol. 2007;20:617-25.

10. Georg J Krinke, The Laboratory Rat. Elsevier Science \& Technology; 2000.

11. Sharp PE. The Laboratory Rat. CRC Press; 1998.

12. Martus W, Kim D, Garvin JL, Beierwaltes WH. Commercial rodent diets contain more sodium than rats need. Am J Physiol Renal Physiol. 2005;288:F428-31. doi: 10.1152/ ajprenal.00310.2004.

13. Provoost AP, de Keijzer MH, Wolff ED, Molenaar JC. Development of renal function in the rat. The measurement of GFR and ERPF and correlation to body and kidney weight. Ren Physiol. 1983;6:1-9.

Copyright (c) 2021 The Author(s); Published by Nickan Research Institute. This is an open-access article distributed under the terms of the Creative Commons Attribution License (http://creativecommons.org/licenses/by/4.0), which permits unrestricted use, distribution, and reproduction in any medium, provided the original work is properly cited. 